\title{
Studying the Amount of Depression and its Role in Predicting the Quality of Life of Women with Breast Cancer
}

\author{
Jalal Shakeri ${ }^{1}$, Sanobar Golshani ${ }^{1}$, Elham Jalilian ${ }^{2}$, Vahid Farnia ${ }^{1}$, Roghieh \\ Nooripour $^{3}$, Mostafa Alikhani ${ }^{1 *}$, Kianoosh Yaghoobi ${ }^{4}$
}

\begin{abstract}
Background: Depression is the most common psychological reactions in women with breast cancer. This study aimed at investigating the amount of depression and its role in predicting the quality of life of women suffering from breast cancer. Materials and Methods: The present descriptive study in volved a correlation method with 98 women living in Kermanshah-Iran with breast cancer. According to the access to the patients and the condition of conducting the research, they were chosen by available sampling. Life quality inventory (World Health Organization, 1989) and depression inventory (Beck et al., 2000) were used to gather the data. Moreover, to analyze the relationships among the variables correlation analysis with Pearson method, as well as multiple regression with the enter method and frequency analysis were applied. Results: The findings revealed that not only is depression high, but also there is a negative significant relationship between depression and the quality of life, with predictive potential. Conclusions: The finding of a relationship between depression and the quality of life points to the need for addressing psychological problems of the affected individuals more appropriately. It is suggested that we consider psychological and educational services for patients in treatment planning to make people aware of different psychological aspects of their disease and ways of struggling and overcoming the problems.
\end{abstract}

Keywords: Breast cancer - depression - life quality - women - Iran

Asian Pac J Cancer Prev, 17 (2), 643-646

\section{Introduction}

Cancer has an incredible growth during recent years. As a matter of fact cancer, which is one of the main issues of 21 century, negatively affects psychological, physical, and social aspects of life (Pourkiani et al., 2010). Researchers have prognosticated that by 2020 the number of cancerous patients will have increased to 15 million (Saki et al., 2011). It is believed that breast cancer is the most rampant kind of cancer among women (Safaie et al., 2007). Unfortunately the frequency of cancer is increasing, $1 \%$ to $2 \%$ among developed countries and about $5 \%$ among developing countries (Agha-Brari et al., 2006). Cancer as a constant incurable disease affects the health and life quality of people, psychological life directly.

Life quality is the degree of individuals' feelings of their abilities about physical, emotional and social performances (Donald, 2002). Some studies about cancer patients revealed that severity of disease and the spiritual pressure affect life quality. Thus recognizing related factors to life quality is of great importance, for it helps to experience high life quality. There has paid little attention to the perception of life quality and the related factors in the life of afflicted women, hence recognizing the amount of life quality and related factors helps the health personnel to direct their activities toward improving health level and life quality (Northouse et al., 1999).

Depression has been recognized as a mental disorganization from a long time ago. Its importance has been in the center of attention since last 2 decades, for it bothers the patients and imposes burdensome expenses to treatment budgets of the peoples (Saatchi et al., 2011). Dadsetan and Mansour (1990) defined depression as an unpleasant mental mode appeared by disgust and despair which is often accompanied by some anxiety (Dadsetan and Mansour, 1990).

Various studies have shown that 50 to 80 percent of the breast cancer patients suffer from psychiatric disorders. The most common psychiatric disorder is adjustment disorders while the second psychiatric is depression (Akechi et al., 2001; Massie, 2004). Accordingly it is supposed that this factor can be one of the most significant

${ }^{1}$ Psychiatry of Department, Substance Abuse Prevention Research Center, Farabi Hospital, Kermanshah University of Medical Sciences, ${ }^{4}$ Young Researchers and Elite Club, Kermanshah Branch, Islamic Azad University, Kermanshah, ${ }^{2}$ Department of Psychology and Educational Sciences, Urmia University, Urmia, ${ }^{3}$ Department of Counseling, Faculty of Education \& Psychology, Alzahra University,Tehran,Iran*For correspondence: Mostafaalikhani18@gmail.com 
related factors to life quality of the women breast cancer. As a result finding the quality of this relationship can help these patients to enhance their social activities. Based on the aforesaid points it seems, that life quality of the afflicted women has relationship with depression. In this paper the amount of depression and its relationship with life quality has been studied. Previous studies showed that not only investigating the multiple relationship of related factors to life quality but also such relationships among the women with breast cancer have been neglected. According to the gap in previous studies, investigating these factors and relationships are of great importance. Likewise confirming relationship between life quality and depression leads to a better perception of cognitive factors in life and health of the afflicted women. Except for the aforesaid advantages, confirming the existence of these relationships will be important for clinical performances, for it helps the medical personnel not only to deal with the problems more comprehensively and recognize the related factors to the disease, but also consider such factors in their planning.

\section{Materials and Methods}

The present study was approved by ethic committee of Kermanshah University of Medical Science. This study was a kind of descriptive ones which was done by correlation method and is mostly applied for description and prediction (Biabangard, 2008). This study aimed at finding the role of depression in predicting life quality of the people with breast cancer. The population was all the women with breast cancer who referred to oncology center of Emam Reza hospital, Kermanshah-Iran during 20132014. The sample was 98 , chosen by available sampling method, whose age range was from 26 to 75 . The mean and standard deviation of their age were 47.60 and 14.05 respectively. Two questionnaires were used to gather data.

Life quality inventory: this inventory was presented in 1989 by World Health Organization which includes 26 items lying on a 5 degree Likert-type spectrum. This inventory has 4 subscales and 1 total scale. Subscales are physical health, psychological, social relationship, and environmental domains. Total score of life quality is achieved by the sum of subscales scores (World Health Organization, 1989). This inventory has been standardized in Iran, by Nasiri (2006). Rahimi and Khayer (2009), reported its reliability for total score as 0.88 and for the subscales, namely physical health, psychological, social relationship, and environmental as $0.70,0.77,0.65$, and 0.77 respectively (Rahimi and Khayer, 2009).

Beck depression inventory (BDI): in this study revised
Beck depression inventory was used. As a matter of fact second edition is the revised version of Beck depression method which was designed to evaluate intensity of depression. This inventory consists of 21 items in which higher score mark higher depression. In a study, Gharaie (2003) reported both the Cronbach's alpha of the inventory as 0.78 and the reliability of test-retest during 2 weeks as 0.73 (Gharaie, 2003). Beck, Steer and Brown (2000) described the internal constancy and Cronbach's alpha coefficient of the inventory as 0.86 from 0.73 to 0.92 (Beck et al., 2000). Likewise Cronbach's alpha coefficient for patients and non-patients were 0.86 and 0.81 respectively.

\section{Results}

To show the condition of the variables, descriptive indexes are presented in Table 1. Depression mean was 24.14 which mark the existence of depression among people. Depression standard deviation indicates that depression has a high sprawl among people. The measure of skewness and kurtosis signs the scores of patients are near to the normal pattern.

At first stage, depression of the patients was studied by frequency analysis, percentage, and cumulative percentage. The findings are presented in Table 2.68 women have serious depression which marks the critical condition of the patients. Besides just $12.2 \%$ of all have no or low depression which indicates that not only is depression high among people, but also health condition affects depression as the rate of health is so low in depression.

Table 3, reveal that depression has a negative correlation with all components of life quality and all the relationships are significant $(\mathrm{P}<0.01)$.

In this study, it was hypothesized that depression can predict life quality, therefore multiple regression analysis was done by enter method. The findings showed that depression can significantly predict all the components of life quality (Table 4). Besides standard regression

Table 2. Description of the Amount of Depression in Patients

\begin{tabular}{lccc}
\hline $\begin{array}{l}\text { Levels of } \\
\text { Depression }\end{array}$ & Frequency & Percent & $\begin{array}{c}\text { Cumulative } \\
\text { Percent }\end{array}$ \\
\hline No depression & 4 & 4.1 & 4.1 \\
low depression & 8 & 8.1 & 12.2 \\
Moderate depression & 18 & 18.4 & 30.6 \\
serious depression & 68 & 69.4 & 100 \\
\hline Total & 98 & 100 & \\
\hline
\end{tabular}

Table 1. The Modifiers of the Study Variables

\begin{tabular}{|c|c|c|c|c|c|c|}
\hline Variable & Mean & Std & Minimum & Maximum & Skewness & Kurtosis \\
\hline depression & 14.24 & 13.23 & 2 & 51 & 0.26 & -1.03 \\
\hline Physical Health Domain & 19.30 & 6.05 & 7 & 30 & -0.32 & -0.75 \\
\hline Psychological Domain & 17.88 & 3.40 & 10 & 24 & -0.20 & -0.66 \\
\hline Social Relationship Domain & 9.41 & 2.50 & 4 & 14 & 0.04 & -0.87 \\
\hline Environmental Domain & 23.44 & 4.69 & 13 & 37 & 0.27 & 0.61 \\
\hline Total Life Quality & 70.02 & 14.41 & 38 & 98 & 0.24 & -0.42 \\
\hline
\end{tabular}


Table 3. The Results of the Correlation Analysis of Depression Variables With Life Quality

\begin{tabular}{lcccccc}
\hline Variable & 1 & 2 & 3 & 4 & 5 & 6 \\
\hline 1. Depression & 1 & & & & & \\
2. Physical Health Domain & $-0.78^{* *}$ & 1 & & & & \\
4. Social Relationship Domain & $-0.62^{* *}$ & $0.61^{* *}$ & $0.68^{* *}$ & 1 & & \\
5. Environmental Domain & $-0.53^{* *}$ & $0.67^{* *}$ & $0.62^{* *}$ & $0.45^{* *}$ & 1 & \\
6. Total Life Quality & $-0.78^{* *}$ & $0.93^{* *}$ & $0.89^{* *}$ & $0.74^{* *}$ & $0.83^{* *}$ & 1 \\
\hline
\end{tabular}

Table 4. Summary of Life Quality Regression Based on Depression

\begin{tabular}{lcccccrr}
\hline Criterion variables & Predictor variable & R2 & F & P-Value & $\beta$ & t & P-Value \\
\hline Physical Health Domain & Depression & 0.61 & 151.21 & 0.001 & -0.78 & -12.29 & 0.001 \\
Psychological Domain & Depression & 0.55 & 118.56 & 0.001 & -0.74 & -10.89 & 0.001 \\
Social Relationship Domain & Depression & 0.37 & 58.47 & 0.001 & -0.62 & -7.64 & 0.001 \\
Environmental Domain & Depression & 0.27 & 37.20 & 0.001 & -0.53 & -6.09 & 0.001 \\
Total Life Quality & Depression & 0.61 & 152.64 & 0.001 & -0.78 & -12.35 & 0.001 \\
\hline
\end{tabular}

coefficients $(\beta)$ and regression slop meaningfulness test $(\mathrm{t})$ show that depression with negative significant Beta coefficient can predict all the components of life quality. As can be seen in Table 4, depression is able to prognosticate respectively $0.61,0.55,0.37$, and 0.27 of the variance of physical health, psychological, social relationship, and environmental domains. Likewise it can predict 0.61 of the variance of total life quality.

\section{Discussion}

In this study a model was studied which investigates the amount of depression and its role in predicting the life quality of women with breast cancer. In the mentioned model life quality includes 4 subscales, namely physical health, psychological, social relationship, and environmental domains, and a life style total score. This model is theoretically trying to confirm cognitivebehavioral theory. Based on the premises of the theory extrinsic and intrinsic factors like physical disease, economic position, hygiene level, individuals' beliefs and thinking style together affect psychological status, physical health and total life (Ellis, 1994; Meichenbaum, 1997). In this study depression is considered as a status originating from both intrinsic and extrinsic factors. Totally, according to these premises, the relationship of depression with life quality is defined in a way that if the individual is hopeful enough and respects himself, he can have high life quality even facing malignant diseases like cancer; he is able to control his life quality better. In other words this relationship indicates that people who were hopeless and belittled themselves in the time of facing a malignant disease like cancer are more susceptible to have low life quality.

The findings revealed that physical health domain has a negative significant relationship with depression in level 0.01 . Therefore it is concluded that more hope and self-importance leads to higher life quality in physical health domain. In other words low level of depression is accompanied by high life quality. In the second part, psychological domain has a negative significant relationship with depression in level 0.01 .
According to this finding it can be inferred that the more hopeful and self-important the individual is the higher life quality in psychological domain will be. As a result low level of depression is accompanied by high life quality in psychological domain of individuals. Psychological domain of life quality has a considerable negative significant relationship with depression. It means that emotional, cognitive and physical feelings of depression like eating, sleeping and sexual disorder lead to low psychological status; people having these feelings hold low life quality in this domain. Through the third part, social relationship domain has a negative significant relationship with depression in level 0.01 . This finding indicates that high level of hopefulness and self-importance posse higher life quality in social relationship domain. In forth part, environmental domain has a negative significant relationship with depression in level 0.01 , so it is inferred that environmental domain in high level is accompanied by low depression. In other words, the more secure the person in economic, social, hygiene status is, the less depression will have. Therefore low level of depression is accompanied by high life quality through environmental domain. Totally, present study is in accordance with all previous similar studies (Taylor, 2003; Jones and Bartlett, 2004; Williams and Dale, 2006; Hopko, et al., 2008; Asoudikermani, et al., 2010; Hamid, et al., 2011).

The findings of the study can be applied for practical uses. Depression and life quality can investigate the related fundamental psychological processes to cancer among the sufferers. Besides recognizing the psychological fundamental factors of cancerous patients may be practical in treatment planning and activities. Treatment activities can be accompanied by individual and group sessions treating depression. According to the findings of this study and previous studies it is suggested to establish psychological and psychotherapy centers in related units to cancer treatment and referent centers of cancerous patients to do psychological therapy. This helps to enhance the life quality of the patients in order to get used to the disease more easily. 


\section{Acknowledgements}

Authors wish to thank all those people who took part in the study.

\section{References}

Agha-Brari M,Ahmadi F, Mohammadi E, et al (2006). Physical, mental and social components of life quality among women with breast cancer in chemotherapy. J Nurs Res, 1, 55-65.

Akechi T, Nakano T, Okamura H (2001). Psychiatric disorders in cancer Patients: descriptive analysis of 1721 Psychiatric referrals at two Japanese cancer center hospitals. Jap J Clin Oncol, 31, 188-94.

Asoudikermani I, Harizchi-Ghadim S, Piry E, et al (2010). The Study of effect of muscle relaxation on anxiety, depression and life quality among people with cancer in Chemotherapy. Tenth national congress of Iranian scientific association of Psychiatry. Iran.

Beck AT, Steer RA, Brown GK (2000). Manual for the beck depression inventory-II. san antonio, TX: The Psychological Corporation.

Biabangard E (2008). Method of research in psychology and educational sciences. 1thed. Tehran: Dowran.

Dadsetan P, Mansour M (1990). Psychosis. Tehran: Roshd.

Donald A (2002). What is Quality of life? Available at: www. jr2.ox.ac.uk.

Ellis A (1994). Reason and emotion in psychotherapy revised. New York: Kensington.

Gharaie B (2003). Status determination of Identity and relationship between Status determination of Identity with identity styles and depression among teenagers. Unpublished $\mathrm{PhD}$ thesis. Medical sciences university of Iran.

Hamid N, Talebian L, Mehrabizade-Honarmand M, et al (2011). Effective of meaning therapy on depression, anxiety and life quality among people with cancer. J Educat Sci Psychol, 18, 199-224.

Hopko DR, Bell JL, Armento M, et al (2008). Cognitive-behavior therapy for depressed cancer patients in medical care setting. Behavior Therapy, 2, 126-136.

JonesW, Bartlett D (2004). A cancer source book for nurses. 8thed. Philadelphia: Lippincott, Williams and Wilkins.

Massie MJ (2004). Prevalence of depression in patients with cancer. J National Cancer Institute Monographs, 32, 57-71.

Meichenbaum D (1997). The evolution of a cognitive-behavior therapist. In J. K. Zeig (Ed.), The evolution of psychotherapy: The third conference (pp. 96-104). New York: Brunner/ Mazel.

Northouse LL, Caffey M, Deichelbohrer L, et al (1999). The quality of life of African American women with breast cancer. Res Nurs Health, 22, 449-60.

Pourkiani M, Hazrati M, Abbaszade A, et al (2010). Whether rehabilitation is effective in improving the quality of life of patients with breast cancer? Payesh J, 9, 61-68.

Rahimi M, Khayer M (2009). Relationship between models of family relationships and quality of life among students of Shiraz. J Educat Psychol Studies Ferdosi University, 10, 5-25.

Saatchi M, Kamkar K, Asgarian M (2011). Psychological Tests. Tehran: Virayesh.

Safaie A, Zighami B, Tabatabaie HR, et al (2007). Life quality and components with effect on life quality among people with breast cancer in Chemotherapy. Iranian J Epidemiol, 3, 61-66.

Saki O, Hajizade E, Tehranian N (2011). Study of risk of breast cancers components by tree models analysis. Ofogh-Danesh $J, 17,60-68$.
Taylor KL (2003). Psychological adjustment among african american breast cancer patients: one year follow-up results of a randomized psycho educational group intervention. Health Psychol, 22, 310-323.

Williams S, Dale J (2006). The effectiveness of treatment for systematic review. British J Cancer, 94, 372-390.

World Health Organization (1989). Constitution of the World Health Organization. Geneva: Author. 